\title{
Analysis on the Mechanical and Fatigue Properties of Foamed Lightweight Soil
}

\author{
Hong liang $\mathrm{Li}^{1}$, a, Ji shu Sun ${ }^{2, ~ b}, \mathrm{Bao} \mathrm{Li}^{1}$ \\ ${ }^{1}$ Tianjin Municipal Engineering Design \& Research Institute, No. 30 Haitai South Road, Nankai \\ District, Tianjin, 300392, China \\ ${ }^{2}$ School of Civil and Transportation Engineering, Hebei University of Technology, No. 5340 Xiping \\ Road, Beichen District, Tianjin, 300401, China \\ ahlli2014@126.com, bsunjishu76@126.com
}

\begin{abstract}
Keywords: Highway Engineering, foamed lightweight soil, Compressive Strength, fatigue, Flexural Strength

Abstract. The compressive strength, flexural strength and fatigue properties of foamed lightweight soil with different mix proportions were systematically analyzed through experiments in this paper. And the main factors influencing the mechanical and fatigue properties of foamed lightweight soil were studied. Combined with the experimental data, the fatigue equation of foamed lightweight soil was derived. The service life of foamed lightweight soil used for highway subgrade construction material was analyzed according to the stress-strain properties of the actual pavement structure. The results show that the foamed lightweight soil can be used as highway subgrade construction material. These would be beneficial to the popularization and application of foamed lightweight soil.
\end{abstract}

\section{Introduction}

Foamed lightweight soil is a kind of light flow building material which is made of cement, water, foaming agent and other fine aggregates (such as fly ash, etc.) [1][2]. Foamed lightweight soil has the virtues of no compaction and self-forming pouring construction. The density and strength of foamed lightweight soil can be easily adjusted by using the method of adjusting the mix ratio according to the engineering requirements. So the reestablishment, expansion and embankment of highway bridge approach road has been widely used in the highway in recent years [3]. When the highway is being widened, large machinery cannot be used due to site restrictions such as the places of soft soil foundation sections. Therefore embankment widening engineering with foamed lightweight soil has obvious advantages. It is easy to construction, but also speed up the progress of the project.

For a kind of subgrade construction materials, the foamed lightweight soil must have good strength. Meanwhile the highway engineering is subject to repeated function of vehicle load after completion. Good fatigue performance is the basis for ensuring the service life of highway engineering. And at present the research for fatigue characteristics of foamed lightweight soil is relatively rare. The mechanics, fatigue characteristics and their laws of foamed lightweight soil will be systematically analyzed by experimentation in this paper.

\section{Test Scheme}

Mix Proportion of Foamed Lightweight Soil. According to the preliminary experiment results, the mix proportion of foamed lightweight soil in the mechanical and fatigue test is shown in Table 1.

Table 1 Mix proportion of foamed lightweight soil

\begin{tabular}{|c|c|c|c|c|}
\hline Number & T1 & T2 & T3 & T4 \\
\hline Cement $[\mathrm{kg}]$ & 250 & 300 & 350 & 400 \\
\hline River Sand $[\mathrm{kg}]$ & 300 & 300 & 300 & 300 \\
\hline Water [kg] & 208 & 229 & 238 & 255 \\
\hline Foaming Agent [L] & 1.2 & 1.2 & 1.1 & 1.0 \\
\hline
\end{tabular}

Test Method. According to the relevant test method [4][5], The size of specimen for compressive strength tests were selected as $100 \mathrm{~mm} \times 100 \mathrm{~mm} \times 100 \mathrm{~mm}$, and the size of specimen for flexural 
strength and fatigue property tests were $100 \mathrm{~mm} \times 100 \mathrm{~mm} \times 400 \mathrm{~mm}$. The specimens were poured according to the mix proportions in Table 1, and were demolished after 24 hours. Then they were maintained to the age required for the tests.

The fatigue experiment used a three-point loading bending test method. Stress ratio is $0.9,0.8,0.7$, 0.6 and 0.5 respectively.

\section{Test Results and Analysis}

The Compressive Strength. According to the selected mix proportions and test method, the compressive strength of foamed lightweight soil with different mix proportions were tested. The test result is shown in Table 2 .

Table 2 Compressive strength of foamed lightweight soil [MPa]

\begin{tabular}{|c|c|c|c|c|c|}
\hline \multicolumn{2}{|c|}{ Number } & $\mathrm{T} 1$ & $\mathrm{~T} 2$ & T3 & $\mathrm{T} 4$ \\
\hline \multicolumn{2}{|c|}{ Cement [kg] } & 250 & 300 & 350 & 400 \\
\hline \multirow{4}{*}{ Age [day] } & 7 & 0.501 & 0.612 & 0.719 & 0.812 \\
\hline & 28 & 1.025 & 1.289 & 1.543 & 1.739 \\
\hline & 90 & 1.382 & 1.733 & 1.988 & 2.213 \\
\hline & 180 & 1.692 & 2.105 & 2.435 & 2.668 \\
\hline
\end{tabular}

The results show that the compressive strength of foamed lightweight soil increases with the increase of cement content. The amount of cement used in each cubic meter of material increased by $50 \mathrm{~kg}$, the 28 -day compressive strength of foamed lightweight soil increased by about $15 \%$. Moreover, the compressive strength increased significantly with the growth of the curing age. And the compressive strength of foamed lightweight soil grew rapidly before the age of 28 days, and stabilized after 28 days. The change rules of compressive strength with the amount of cement and age changes is shown in Figure 1.

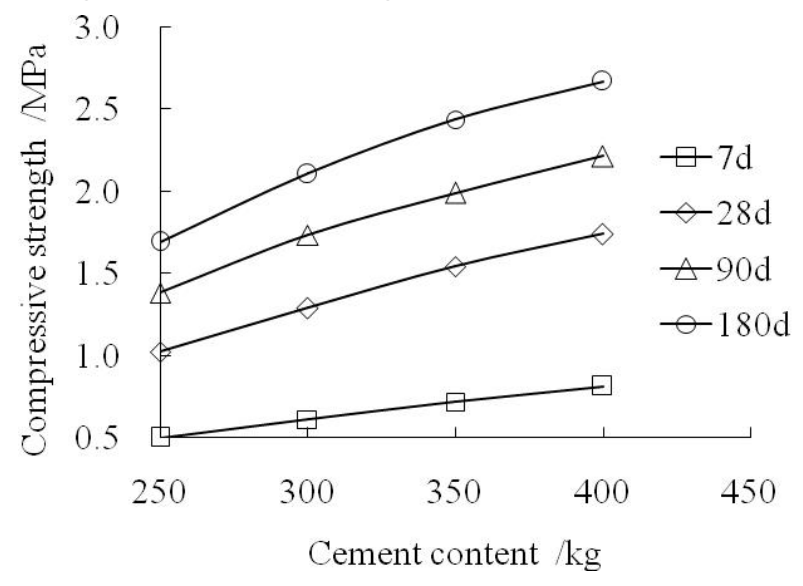

a) The effect of cement content on compressive strength

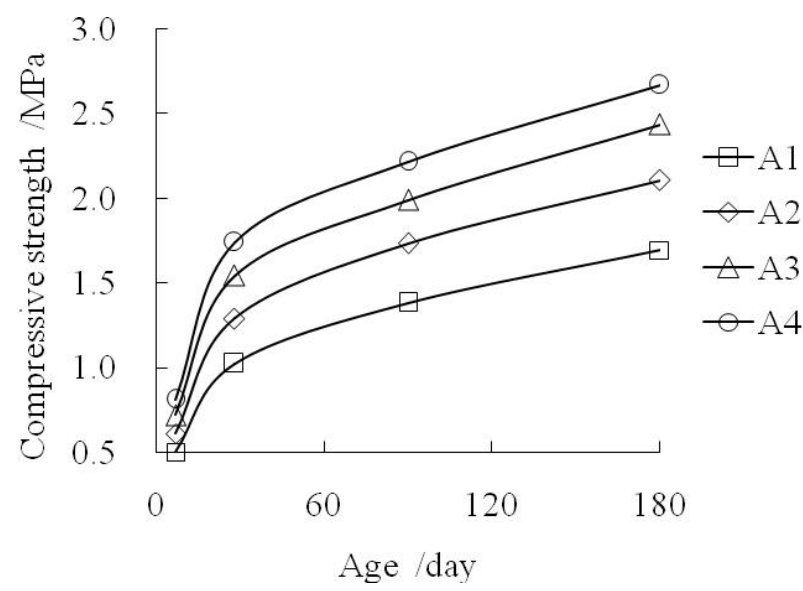

b) The effect of curing age on compressive strength

Fig. 1 Compressive strength of foamed lightweight soil

The Flexural Strength. The flexural strength is the basis for the fatigue experiment and the basic technical parameter that needs to meet the requirement of subgrade construction material. The 90-day flexural strength of foamed lightweight soil with different cement content are measured. The results weres shown in Table 3.

Table 3 Flexural strength of foamed lightweight soil

\begin{tabular}{|c|c|c|c|c|}
\hline Number & $\mathrm{T} 1$ & $\mathrm{~T} 2$ & $\mathrm{~T} 3$ & $\mathrm{~T} 4$ \\
\hline Cement $[\mathrm{kg}]$ & 250 & 300 & 350 & 400 \\
\hline Flexural strength $[\mathrm{MPa}]$ & 0.577 & 0.652 & 0.736 & 0.832 \\
\hline
\end{tabular}

The test results from Table 3 indicate that the cement content has a significant effect on the flexural strength of the foamed lightweight soil. The amount of cement used in each cubic meter of material increased by $50 \mathrm{~kg}$, the flexural strength of foamed lightweight soil increased by about $15 \%$. This is mainly due to the fact that cement is a combination of foamed lightweight soil, when the 
cement content is higher, the more binding material per unit volume will be, the mixture will have the greater the strength. The effect rules of cement content on the flexural strength of foamed lightweight soil are shown in Figure 2.

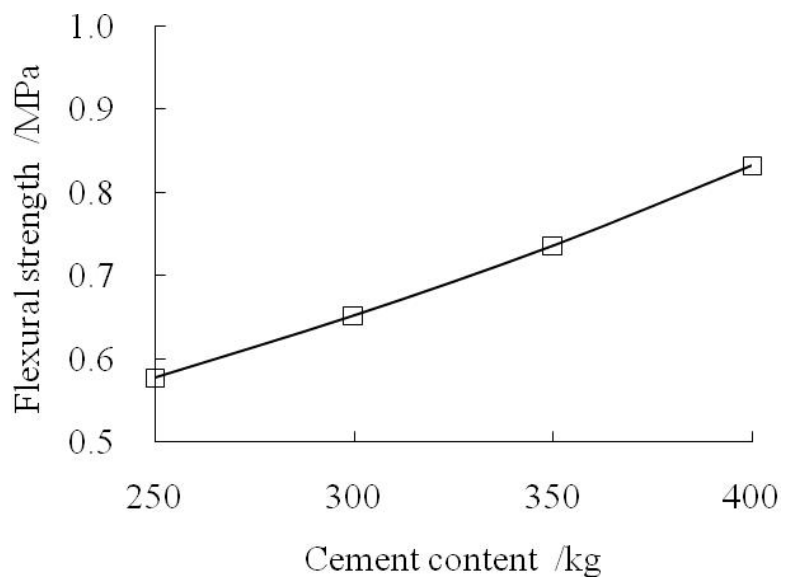

Fig.2 The effect of cement content on the flexural strength of foamed lightweight soil

The Flexural Strength. According to the selected test method, the number of load cycles of foamed lightweight soil with different mix proportion and stress ratios are measured as shown in Table 4.

Table 4 The number of load cycles of foamed lightweight soil

\begin{tabular}{|c|c|c|c|c|c|}
\hline \multicolumn{2}{|c|}{ Number } & T1 & T2 & T3 & T4 \\
\hline \multirow{4}{*}{ Stress ratio } & 0.5 & 138261 & 183208 & 266804 & 403705 \\
\cline { 2 - 6 } & 0.6 & 42432 & 56990 & 79659 & 111288 \\
\cline { 2 - 6 } & 0.7 & 4066 & 5894 & 8364 & 11730 \\
\cline { 2 - 6 } & 0.8 & 555 & 706 & 991 & 1165 \\
\cline { 2 - 6 } & 0.9 & 32 & 40 & 51 & 65 \\
\hline
\end{tabular}

The test results from Table 4 indicate that the cement content has a significant effect on the fatigue properties of foamed lightweight soil materials. In the case of the same conditions, the cement content increase by $150 \mathrm{~kg}$ compared with A4 and A1. When the stress ratio is 0.5 , the number of load cycles can increase by about 3 times. And when the stress ratio is 0.9 , the number of load cycles can increase by about 2 times. It can be seen that the effect of cement content on the fatigue properties of foamed lightweight soil is more obvious at a low stress ratio. In the project, the mix proportions of foamed lightweight soil should be determined according to the specific application conditions, which should meet the strength requirements, but also ensure the service life.

The effect of cement content and stress ratio on fatigue endurance is shown in Figure 3.

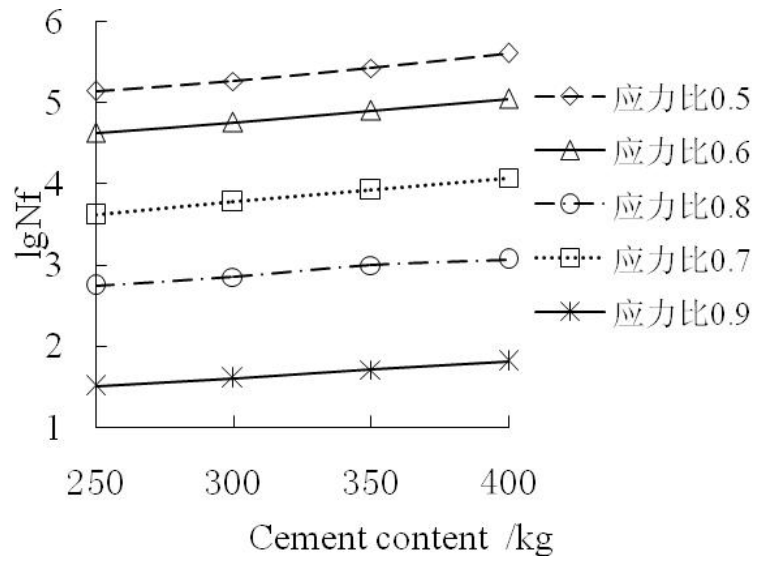

a) The effect of cement content on fatigue properties

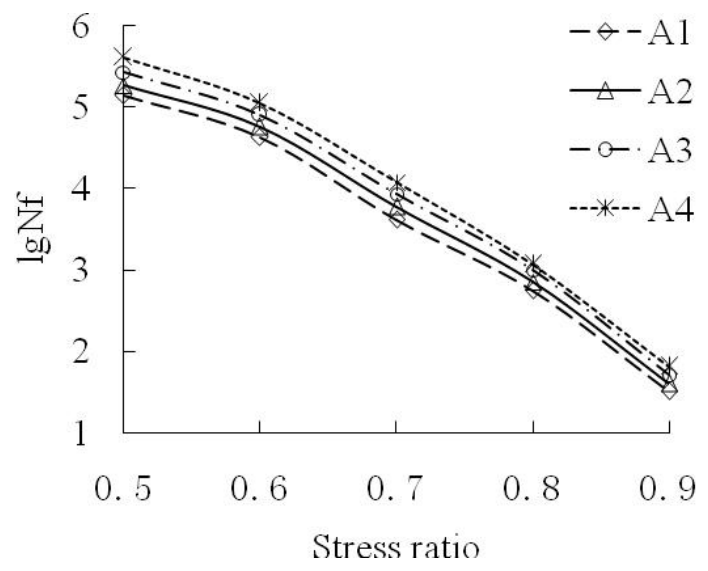

b) The effect of stress ratio on fatigue properties

Fig.3 Fatigue property curve of foamed lightweight soil 
According to the results of fatigue tests, the fatigue equation of foamed lightweight soil can be be described as Eq.(1) (in the case of A1).

$$
\lg N_{f}=9.933-9.155 S \quad R^{2}=0.9783
$$

Where $N_{f}$ is the fatigue endurance of foamed lightweight soil; $S$ is the stress ratio.

The stress delivered to the foamed lightweight soil under standard axle load is around $0.13 \mathrm{MPa}$ for general highways [3]. The value of the fatigue life at this time can be calculated as $7.287 \times 10^{7}$. Simultaneously the fatigue endurance of foamed lightweight soil is sufficient to meet the requirements of the design service life of highways.

\section{Conclusions}

(1) The compressive strength of foamed lightweight soil increases with the increase of cement content. The amount of cement used in each cubic meter of material increased by $50 \mathrm{~kg}$, the 28 -day compressive strength of foamed lightweight soil increased by about $15 \%$. Moreover, the compressive strength increased significantly with the growth of the curing age. And the compressive strength of foamed lightweight soil grew rapidly before the age of 28 days, and stabilized after 28 days.

(2) The flexural strength increases with the increase of cement content. The amount of cement used in each cubic meter of material increased by $50 \mathrm{~kg}$, the flexural strength of foamed lightweight soil increased by about $15 \%$

(3) The cement content has a significant effect on the fatigue properties of foamed lightweight soil materials. When the stress ratio is 0.5 , the number of load cycles can increase by about 3 times. And when the stress ratio is 0.9 , the number of load cycles can increase by about 2 times.

(4) According to the results of fatigue tests, the fatigue equation of foamed lightweight soil is concluded, which can be used as a basis for engineering design.

\section{References}

[1] Xiang Xiao-wei. "Application of foam concrete in road widening project". Chinese Journal of Technology Innovation and Application, Vol. 31 (2013):190-191 (in Chinese).

[2] CECS 249:2008. "Technical specification for cast-in-situ foamed lightweight soil", China Planning Press. (in Chinese).

[3] Wu Hai-gang, Wang Bao-jun, Zheng Yong-hong, et al. "Research on the design method of the large-scale foam light soil for soft ground treatments", Chinese Journal of Railway Engineering, Vol. 2 (2016):28-33 (in Chinese).

[4] Ministry of Communication. "Test methods of cement and concrete for highway engineering", China Communication Press. JTG E30-2005 (in Chinese).

[5] Ministry of Communication. "Test methods of materials stabilized with inorganic binders for highway engineering”, China Communication Press. JTG E51-2009 (in Chinese). 